Manuel Rivera Mateos Doctor en Geografía e Historia. Área de Análisis Geográfico Regional. Departamento de Geografía y Ciencias del Territorio, Facultad de Filosofía y Letras, Universidad de Córdoba (España). Córdoba, España [manuel.rivera@uco.es].

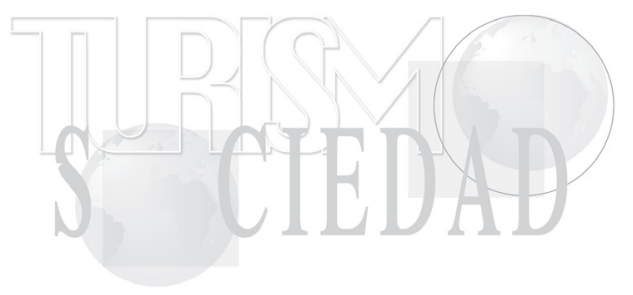

\section{LA OFERTA COMERCIAL DE TURISMO ACTIVO DE NATURALEZA EN ESPAÑA: ESTRUCTURACIÓN, TENDENCIAS RECIENTES Y CONTEXTUALIZACIÓN TERRITORIAL 1}

1 Fecha de recepción: 14 de abril de 2015

Fecha de modificación: 22 de mayo de 2015

Fecha de aceptación: 11 de junio de 2015

\footnotetext{
Para citar el artículo: Rivera, M. (2015). La oferta comercial de turismo activo de naturaleza en España: estructuración, tendencias recientes y contextualización territorial. Turismo y Sociedad, XVI, pp. 85-108 DOI: http://dx.doi.org/10.18601/01207555.n16.06
}

\section{THE COMMERCIAL OFFER \\ FOR ACTIVE TOURISM \\ NATURE-BASED IN SPAIN: \\ STRUCTURING, RECENT \\ TRENDS AND TERRITORIAL \\ CONTEXT}

\section{Resumen}

Este trabajo pretende realizar un análisis actualizado de la situación, problemática, evolución reciente y desarrollo territorial de la oferta comercial del turismo activo y deportivo de naturaleza en España, para lo cual se ha efectuado una exploración específica de fuentes primarias y secundarias, y una revisión bibliográfica complementaria. Además de realizar una aproximación teórica y conceptual de las actividades de turismo deportivo de naturaleza y su contextualización en el ámbito de la planificación y ordenación turística del país, se estudia la estructuración de la oferta y el tejido empresarial, sus características fundamentales y problemática, así como su distribución y significación geográfica. Por último, se describen las tendencias recientes de nuevos productos turísticos, o de renovación o adaptación a la demanda de otros más tradicionales.

Palabras clave: Turismo activo, turismo deportivo de naturaleza, deportes de naturaleza, oferta empresarial, España.

\begin{abstract}
This research tries to make an analysis of the situation, problems, recent evolution and territorial development of the commercial offer of active and sport naturebased tourism in Spain, which was performed a specific operation of primary and secondary sources and a literature review complementary. In addition to theoretical and conceptual approach of the activities of sports nature based tourism and its contextualization in the field of tourism planning and management in the country, is studied the structure of supply and the business, its fundamental characte-
\end{abstract}


ristics and problems and its distribution and geographical significance. And finally, described recent trends of new tourism products or renewal or adaptation to the demand for more traditional.

Keywords: Active tourism, sport tourism nature-based, nature sports, commercial offer, Spain.

\section{Introducción: marco conceptual y político-administrativo del turismo activo en España}

De manera general, la noción de turismo activo puede caracterizarse por su contraposición al turismo pasivo, contemplativo o sedentario, de corte convencional, las estancias vacacionales tradicionales de mero descanso y esparcimiento, el turismo residencial o las visitas turísticas reducidas al conocimiento y contemplación de determinados recursos y destinos. De hecho, considerando las motivaciones, la actitud y el "grado de participación" de los turistas en sus viajes, cada vez más proliferan los esquemas duales de distinción entre ambas formas de hacer turismo que integran un "binomio" que refleja realidades turísticas contrastadas² (López, 1993; Vera, 1997). De esta manera, el turismo pasivo se identifica habitualmente con el turismo de masas y fordista (sol y playa, turismo residencial, vacaciones tradicionales de descanso y relax, visitas culturales, turismo de salud y

2 En esta primera aproximación al turismo activo en un sentido amplio, conectamos con las clasificaciones existentes del turismo relacionadas con "opciones duales" dentro de las categorías turísticas: turismo rural/turismo urbano, turismo nacional/turismo internacional, turismo litoral/turismo de montaña, turismo masivo convencional/turismo alternativo, turismo itinerante/turismo residencial. Entre ellas, con alguna frecuencia se ha recogido entre los investigadores el concepto de "turismo activo" frente al "turismo pasivo", ateniéndose a la dialéctica entre las motivaciones, los comportamientos, el "grado de participación" del turista en la experiencia final del viaje y la diversidad de componentes que intervienen en este, configurando este dualismo como marco de referencia y recurso terminológico de diferenciación de estos turismos. diversas formas de turismo rural y cultural sin apenas consumo de actividades físicorecreativas). Por su parte, el turismo activo se relaciona con aquellas modalidades en las que a priori se requiere una implicación activa del turista y la práctica de actividades recreativas dinámicas, participativas y de carácter físicodeportivo, estando más ligadas, por tanto, a las formas de turismo posfordista.

No obstante, el turismo activo difícilmente puede definirse con propiedad como un segmento de demanda turística propiamente dicho, una tipología turística específica ${ }^{3}$ o un turismo genérico, como el turismo de naturaleza, el rural o el cultural, sino como una "forma o modo de hacer turismo", una categoría flexible y genérica o un concepto "paraguas" que, en realidad, agruparía múltiples actividades, prácticas, tipologías y productos turísticos, tanto de índole recreativa (outdoor recreation, en el ámbito anglosajón) como cultural, deportivo o de viajes de aventura, cuyo rasgo común sería la búsqueda de unas vacaciones no meramente contemplativas, de descanso pasivo o relax, sino específicamente dinámicas, en las que el turista se convierte en sujeto activo del viaje buscando, por ejemplo, la actividad, la movilidad, la deportividad, etc. (Nasser, 1995).

Por tanto, desde nuestro punto de vista, el término "turismo activo" ha de entenderse más propiamente, en sentido estricto, como similar o casi sinónimo del concepto de "vacaciones activas" (activity holidays en la

\footnotetext{
3 Entendemos como turismos específicos aquellos ligados a recursos y productos capaces de captar un determinado segmento de demanda y un número significativo de consumidores que se ven atraídos por su disfrute generando desplazamientos hacia los destinos donde se encuentran. En cambio, consideramos como turismos genéricos aquellos que presentan unas características generales en cuanto a perfil sociodemográfico y económico de la demanda, entorno geográfico y estilos y personalidad de vida, que se corresponden con un cuadro de motivaciones variado y amplio, y que puede asociarse a diversos turismos específicos y actividades complementarias para ocupar el tiempo de ocio principalmente el turismo en el medio rural, el turismo de naturaleza y el turismo cultural y de incentivos de empresa.
} 
terminología anglosajona), cuya definición ha sido establecida por la Organización Mundial del Turismo como "aquellas durante las cuales los turistas se dedican a actividades culturales, artesanales, deportivas, etc., con la intención de realizarse personalmente y desarrollar su personalidad" (WTO, 1985). Se trata lógicamente de una definición muy amplia y genérica al incluir un universo variado y numeroso de actividades, tanto de índole recreativa al aire libre (outdoor recreation, en la acepción anglosajona) como de carácter cultural, deportivo o de aventura, aunque con el denominador común de la búsqueda de unas vacaciones específicamente dinámicas, de carácter motriz e interactivo, en las que el turista puede convertirse en sujeto activo y protagonista de la experiencia viajera, no contento ya con "ver", sino prefiriendo "hacer", siendo esta una "megatendencia turística" que viene detectándose en España desde principios de los años ochenta al menos (Miguel, 1984; Figuerola, 1986 y Granados, 1998).

De este modo, incluiría tanto motivaciones "no de masas" que pueden dar lugar a turismos específicos (como el de aventura en la naturaleza, el científico, el educativo, el de reuniones e incentivos de empresa, el deportivo al aire libre, etc.), así como también otras más ligadas al "turismo de masas" (como las integradas por las actividades recreativas en parques temáticos, acuáticos y de atracciones), por lo que existen ciertas dificultades para situar conceptualmente esta noción al solaparse o asociarse frecuentemente con diferentes tipos de turismos genéricos (como el de sol y playa, el cultural, el urbano, el de naturaleza o el rural) o específicos (como el agroturismo, el ecoturismo o el turismo recreativo periurbano). Las actividades recreativas "activas" pueden, por otra parte, constituirse en motivo principal del viaje y conformar un turismo específico de "vacaciones activas", pero, otras veces, y de manera más frecuente, son más bien actividades secundarias como oferta complementaria de otras principales e integradas dentro de la oferta genérica de algunos destinos o segmentos turísticos, lo que complica aún más su delimitación.

En cualquier caso, en las normativas autonómicas de turismo en España ha acabado por imponerse en las dos últimas décadas el concepto de "turismo activo" como el integrado por aquellas actividades físicodeportivas, motrices y de "aventura controlada”, más o menos especializadas y con un fuerte componente lúdico-recreativo, que se practican sirviéndose básicamente de los recursos que ofrece la naturaleza en el medio en el que se desarrollan (terrestre, subterráneo, acuático, subacuático, aéreo, etc.) y a las cuales les es inherente el factor riesgo o cierto grado de esfuerzo físico y destreza para su práctica.

En 2014 eran ya doce las comunidades autónomas españolas (en adelante CC. AA.) que tenían reguladas específicamente estas actividades utilizando la denominación indicada (tabla 1), aunque otras, como Extremadura o las Islas Baleares, vienen trabajando en la línea de una futura ordenación del sector, o bien, tienen reguladas algunas actividades de importante frecuentación en su ámbito territorial, como es el caso del senderismo en el País Vasco, la observación de cetáceos en Canarias o los deportes con vehículos de motor en Madrid. Por tanto, hoy en día, desde las administraciones públicas suele asumirse la necesidad de un marco regulador de dichas prácticas, tanto por el carácter singular de estas actividades y la seguridad que requieren para los usuarios como por los escenarios naturales que se ven afectados, así como de políticas específicas de fomento y promoción de este segmento emergente y de interés estratégico para algunos destinos del interior y del litoral. 
Tabla 1. Normativa autonómica reguladora del turismo deportivo de naturaleza en 2008

\begin{tabular}{|c|c|}
\hline $\begin{array}{l}\text { Normativa } \\
\text { autonómica }\end{array}$ & Reglamentos \\
\hline Andalucía & $\begin{array}{l}\text { Decreto } 20 / 2002 \text {, de } 29 \text { de enero, de turismo en el medio rural y turismo activo. } \\
\text { Orden de } 20 \text { de marzo de } 2003 \text { conjunta de las Consejerías de Turismo y Deporte y Medio Am- } \\
\text { biente, por la que se establecen obligaciones y condiciones medioambientales para la práctica de } \\
\text { las actividades integrantes del turismo activo. }\end{array}$ \\
\hline Aragón & $\begin{array}{l}\text { Decreto 55/2008, del } 1 .^{\circ} \text { de abril, del Gobierno de Aragón, por el que se aprueba el Reglamento } \\
\text { de las empresas de turismo activo. }\end{array}$ \\
\hline Asturias & Decreto $111 / 2014$, del 26 de noviembre, de turismo activo. \\
\hline Cantabria & $\begin{array}{l}\text { Decreto } 31 / 1997 \text {, del } 23 \text { de abril, por el que se regulan los alojamientos y actividades en el medio } \\
\text { rural de Cantabria (parcialmente derogado). }\end{array}$ \\
\hline Castilla-La Mancha & Decreto $77 / 2005$, del 28 de junio de 2005 , de ordenación de las empresas de turismo activo. \\
\hline Castilla y León & $\begin{array}{l}\text { Decreto 96/2007, del } 27 \text { de septiembre, por el que se regula la ordenación de las empresas de } \\
\text { turismo activo en Castilla y León. } \\
\text { Orden CYT 1865/2007, del } 15 \text { de noviembre, por el que se desarrolla el Decreto 96/2007. }\end{array}$ \\
\hline Cataluña & $\begin{array}{l}\text { Decreto 56/2003, del } 4 \text { de febrero, por el que se regulan las actividades físico-deportivas en el } \\
\text { medio natural. } \\
\text { Orden PRE/361/2004, del } 6 \text { de octubre, por la que se modifica el catálogo de actividades físico- } \\
\text { deportivas en el medio natural. }\end{array}$ \\
\hline $\begin{array}{l}\text { Comunidad } \\
\text { Valenciana }\end{array}$ & $\begin{array}{l}\text { Decreto 20/2012, del } 27 \text { de enero, del Consell, regulador del turismo activo en la Comunidad } \\
\text { Valenciana. }\end{array}$ \\
\hline Galicia & $\begin{array}{l}\text { Decreto } 42 / 2001 \text {, del } 1 .^{\circ} \text { de febrero, de refundición en materia de agencias de viajes, guías de tu- } \\
\text { rismo y turismo activo (art. } 42 \text { a } 51 \text { y disposiciones adicionales } 1 .^{\mathrm{a}}, 2 .^{\mathrm{a}} \text { y transitoria } 3 .^{\mathrm{a}} \text { y final } 2 .^{\mathrm{a}} \text { ). }\end{array}$ \\
\hline La Rioja & $\begin{array}{l}\text { Decreto 14/2011, del } 4 \text { de marzo, por el que se aprueba el reglamento de desarrollo de la Ley } \\
\text { 2/2001, del } 31 \text { de mayo, de turismo de La Rioja. }\end{array}$ \\
\hline Murcia & Decreto 320/2007, del 19 de octubre, que regula las empresas de turismo activo de la región de Murcia. \\
\hline Navarra & $\begin{array}{l}\text { Decreto Foral 288/2004, del } 23 \text { de agosto, por el que se aprueba el reglamento para el ejercicio de } \\
\text { la actividad de las empresas dedicadas a la prestación de servicios de turismo activo y cultural. }\end{array}$ \\
\hline
\end{tabular}

Fuente: Mesa del Turismo de España y Legislación Autonómica de Turismo. Elaboración propia.

A partir de 2010 se han dado también algunos pasos importantes para el impulso y tratamiento adecuado de este subsector turístico en España, como es el caso de la entrada en vigor y desarrollo posterior de la Ley 17/2009, del 23 de noviembre, sobre libre acceso a las actividades de servicios y su ejercicio, que transpone a la legislación española la Directiva 2006/123/CE del Parlamento Europeo y del Consejo, de 12 de diciembre de 2006, relativa a los servicios en el mercado interior ${ }^{4}$. Estas normativas están

4 Más conocida como Directiva Bolkstein (Diario Oficial L 376 de 27-12-2006). La derogación de la normativa turística facilitando ya, sensiblemente, la apertura de nuevas empresas de turismo activo y -lo que resulta más importante aún- el afloramiento

estatal residual, y la adaptación y actualización de las normativas autonómicas sobre turismo se han producido básicamente en 2010 y, además de haber promovido una cierta armonización y convergencia de las legislaciones de las CC. AA. sobre turismo activo, están contribuyendo a una simplificación notable de los trámites administrativos para la puesta en funcionamiento y desarrollo de las empresas de turismo activo con la introducción, por ejemplo, de medidas como la inscripción en los registros de turismo con base en una declaración responsable que permite a las empresas entrar en funcionamiento inmediatamente sin trámites administrativos previos de autorizaciones sectoriales, controles, inspecciones y/o medidas cautelares de la administración, que alargaban y dificultaban mucho anteriormente la apertura de este tipo de establecimientos. 
legal de otras muchas en situación anterior de clandestinidad y economía sumergida. Esto lo hemos podido comprobar expresamente en Andalucía (figura 1), gracias a las medidas introducidas sobre libertad de establecimiento de los prestadores de servicios en cualquier país miembro de la UE, la agilización y simplificación de trámites administrativos, la liberalización de dichos servicios y la supresión de algunos obstáculos jurídicos y administrativos que, en el ámbito de las CC.AA., estaban constriñendo seriamente el desarrollo de este tipo de empresas turísticas: exigencia de titulaciones oficiales específicas para monitores y directores técnicos, sometimiento a regímenes de autorización diversos según CC. AA., autorizaciones sectoriales previas no turísticas que impedían la inscripción de funcionamiento en los registros de turismo, condiciones excesivas y poco meditadas en cuanto a coberturas de los seguros de responsabilidad civil, etc.

Figura 1. Evolución del número de empresas de turismo activo en la naturaleza inscritas en el Registro de Turismo de Andalucía (2002-2010)

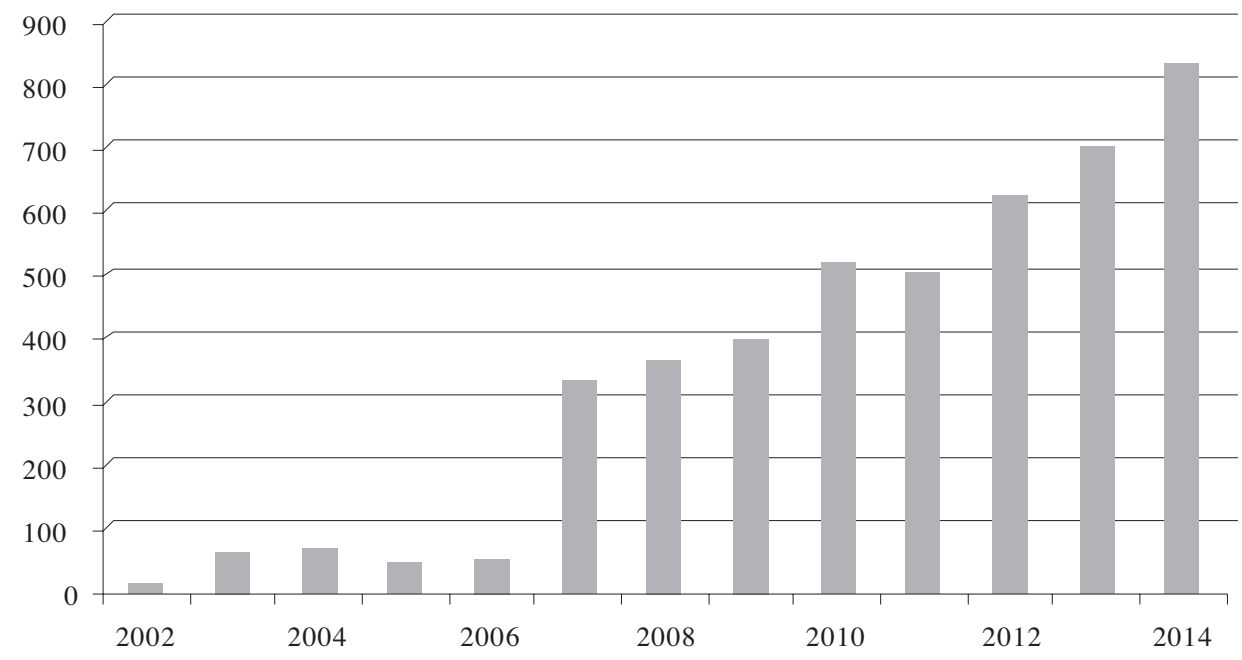

Fuente: Consejería de Turismo, Comercio y Deporte (Junta de Andalucía).

Registro de Turismo de Andalucía. Elaboración propia.

Aunque nosotros preferimos denominar al segmento turístico integrado por la oferta de deportes de naturaleza, de aventura y actividades físico-deportivas al aire libre como "turismo deportivo de naturaleza", tal como se hace en algunos países de larga tradición en su desarrollo como Francia (Bourdieu, 1995), hemos optado por emplear el término de "turismo activo" por ser precisamente el más aceptado en España al haberse consolidado este tanto en el ámbito político-administrativo antes referido como entre los usuarios, operadores y empresas ofertantes de estas actividades.

En cualquier caso, el concepto de "turismo activo", tal como se utiliza en el argot turístico español, integra una gama amplia y diversa de actividades turístico-deportivo-recreativas en escenarios también variados, con técnicas, materiales y personal especializado de apoyo ciertamente diferentes, y con prácticas y viajes que van desde los adaptados a grupos familiares hasta a colectivos de amigos, in- 
centivos de empresas, centros de educación ambiental, campamentos juveniles, deportistas federados o "aventureros" que buscan una alternativa y un cambio para ocupar su tiempo libre u organizar sus vacaciones.

Es, por tanto, un concepto "paraguas" que engloba un sinfín de actividades y modalidades turístico-deportivas en la naturaleza, que la mayoría de las veces se comportan como una oferta complementaria asociada a turismos temáticos diferentes (rural, de naturaleza, de sol y playa, invernal y de montaña, de reuniones de empresas, etc.) y a alojamientos de diverso tipo, mientras que otras se configuran como ofertas especializadas que constituyen la principal motivación del desplazamiento (turismo deportivo de naturaleza específico), particularmente en destinos también especializados y con una imagen de marca especializada (rafting en la Sierra de Guara, surf y kitesurf en Tarifa, piragüismo y descenso de cañones en la zona oriental de Asturias, deportes de invierno en estaciones de montaña de Aragón, Cataluña o Sierra Nevada, entre otras). Y no debemos olvidar que el ocio activo de naturaleza genera también desplazamientos frecuentes y de corta duración (excursionismo) desde la ciudad a los espacios periurbanos de cierta calidad ambiental y recreativa, o a zonas rurales y espacios protegidos cercanos, presentando un gran potencial de demanda futura de productos de turismo deportivo de naturaleza.

La proliferación relativamente reciente de esta amplia gama de actividades de ocio activo y deportes de naturaleza en España ha de entenderse en el contexto de la revalorización y puesta en valor de recursos infrautilizados con fines recreativos y de ocio en los destinos rurales y de naturaleza emergentes, así como de la recualificación y diversificación productiva de los destinos litorales más o menos maduros, como estrategia, en ambos casos, de competitividad, diferenciación y posicionamiento en el mercado turístico, e integración de una oferta complementaria atractiva para estos destinos (Rivera, 2010).

Unas veces, en concreto, estas actividades contribuyen a incrementar y sostener el atractivo de los destinos ya sea a) mediante la integración de las prácticas deportivas de naturaleza en la promoción de los alojamientos rurales y en los espacios naturales protegidos, b) por medio del sistema de conformación de paquetes integrales con actividades (estaciones de montaña, por ejemplo), hasta el uso de estas prácticas como factor de desestacionalización, o bien, c) a través de la organización de equipamientos y eventos deportivos (turismo náutico, sobre todo). Pero la generalización de estas prácticas en las que se conjugan en un sentido amplio y flexible el deporte, el medio ambiente y el turismo es, sobre todo, consecuencia de la interacción de una serie de factores demográficos, culturales y económicos característicos de las nuevas sociedades posmodernas: interés creciente por la naturaleza y el deporte de las sociedades urbanas; cambio de motivaciones turísticas; tendencia a la fragmentación de las vacaciones; nuevos paradigmas sociales presididos por la salud, el cuidado del cuerpo, la huida del medio urbano, de la rutina y del estrés; el placer de las nuevas experiencias de riesgo y emoción en contacto directo con el medio natural (Medina y Sánchez, 2005; Rivera, 2007 y González, 2008).

En España, la práctica de actividades físicodeportivas de naturaleza con una vertiente recreativa y turística tiene en algunos casos una larga tradición, como ocurre con la caza y la pesca deportiva en aguas continentales, el montañismo o el senderismo. Pero la emergencia de los nuevos deportes de aventura y riesgo, así como también las denominadas "empresas de turismo activo" es, en cambio, reciente, de finales de los años ochenta, como también lo es la consolidación de otras actividades que tenían una práctica más limitada, o la diversificación e innovación de deportes 
preexistentes con nuevas submodalidades y formas de práctica.

\section{La estructuración de la oferta y la caracterización del tejido empresarial}

La oferta de empresas y entidades de turismo activo de naturaleza, que generalmente es complementaria de otras principales, es amplia y diversa en cuanto a sus propuestas de actividades (multiaventura, deportes blandos de naturaleza, deportes de aventura, educación ambiental, pesca y caza, campamentos juveniles, outdoor training, actividades de incentivos, parques de aventura, etc.). Esta oferta ha experimentado un auge muy relevante en los últimos quince años, tal como revelan las cifras de las empresas promocionadas en FITUR Active, de la Feria Internacional de Turismo de Madrid, desde su creación en 1994, con un crecimiento porcentual de un $139 \%$ de entidades incluidas en la guía oficial hasta 2010 (figura 2). No obstante, estos datos no reflejan la verdadera magnitud de la oferta nacional real existente, que es difícil de determinar cuantitativamente porque no hay estadísticas ni registros oficiales fiables ni operativos en muchas comunidades autónomas.
La Asociación Nacional de Empresas de Turismo Activo (ANETA), como máxima asociación empresarial representativa del sector e integrada en la Confederación Europea de Empresas de Turismo Activo (EC-OE), en los últimos años ha venido hablando de un subsector turístico de más de 1500 empresas especializadas, con un volumen de negocio de alrededor de 150 millones de euros anuales, 8000 trabajadores fijos y más de 10000 eventuales. Pero, sin duda, habría que elevar estas cifras si consideramos la oferta no reglada y clandestina, la de entidades sin ánimo de lucro y de carácter público, las empresas de alojamiento u otros servicios turísticos que complementan su cartera de productos con actividades de turismo activo, así como también a las empresas no promocionadas en los canales turísticos convencionales. De hecho, en este trabajo, por medio de la consulta y el contraste complementario de diversas fuentes primarias y secundarias, hemos intentado aproximarnos mejor a esta realidad empresarial y turística, que ciertamente tiene una mayor significación cuantitativa y cualitativa que la que apunta a la propia asociación empresarial antes referida, como al menos así lo reflejan los datos y resultados empíricos finalmente obtenidos.

Figura 2. Evolución del número de empresas de turismo activo en la naturaleza promocionadas en los catálogos oficiales de Fitur (1995-2010)

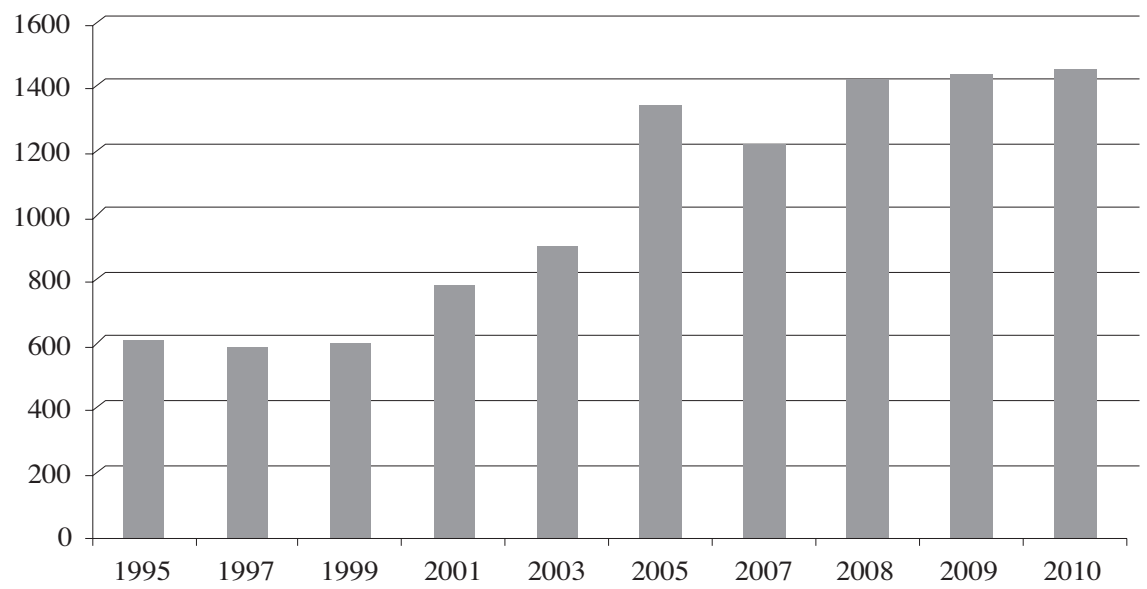

Fuente: Turespaña. Guías Fitur Active de Fitur. Elaboración propia. 
En cualquier caso, esta oferta presenta formatos comerciales diferentes (actividades independientes y especializadas, combinadas, en colaboración con otras empresas, etc.); además, es muy joven y de pequeñas dimensiones, insuficientemente profesionalizada a pesar de la mayor conciencia de los empresarios sobre la necesidad de la formación y la calidad, y presenta productos poco estandarizados; por añadidura, tiene productos que en buena parte no están bien estructurados. Esto ciertamente dificulta su comercialización y su mejor aprovechamiento por las economías locales, y dificulta que España sea un destino visible, afianzado y atractivo en el ámbito internacional (Instituto de Turismo España, 2008). Una de las razones de estas deficiencias es, sin duda, la propia realidad de la oferta empresarial de turismo de naturaleza en España, basada en microempresas creadas con una inversión inicial pequeña, con graves dificultades para consolidarse y en las que el propietario se involucra tanto en la gestión del negocio como en la realización y conducción de actividades o, como mucho, tiene contratado a uno o dos trabajadores.

Como se refleja en la figura 3 , la oferta comercial es considerablemente amplia en el caso de las actividades terrestres y acuáticas, quedando a mucha distancia las actividades de nieve y aéreas. El senderismo, las rutas, excursiones ecuestres y el cicloturismo-bicicleta de montaña son las actividades estrella en el medio terrestre, mientras que el piragüismo, el barranquismo-descenso de cañones y la vela lo son en el medio acuático. En los últimos años han surgido también los programas de multiaventura y juegos físico-deportivos de habilidad en la naturaleza (campamentos juveniles, ofertas para grupos en complejos turísticos, actividades de incentivos, outdoor training y team building, raids, parques acrobático-forestales y de aventura, gymkhanas, etc.), así como la integración de los deportes de naturaleza en la oferta de los centros de educación ambiental (granjas-escuela, aulas y centros de interpretación de la naturaleza, aulas del mar, etc.), las "vacaciones activas veraniegas" en las estaciones de esquí y montaña (Rivera, 2011) $)^{5}$, los deportes de aventura especializados, estructurados y con marca propia en zonas como la Sierra y Cañones de Guara y la cuenca del Noguera Pallaresa, las escuelas de buceo y kite surf, las vías ferrata y de escalada, las pruebas de orientación/ geocaching o los centros BTT y estaciones verdes ya citados.

No obstante, la mayoría de las veces el producto turístico final suele contar con infinidad de deficiencias: escasa estructuración de la oferta por la falta de organización de destinos; insuficiencia de profesionales cualificados; desconocimiento por parte del resto de empresas del sector turístico; alta fluctuación de la demanda; dificultades relacionadas con la gestión del riesgo por el alto coste de mantenimiento del material; precio alto de los seguros de responsabilidad civil y accidentes, etc. En la práctica escasean los verdaderos productos definidos, comercializados y bien gestionados por especialistas, productos que intenten aprovechar las ventajas competitivas de algunos destinos en determinados recursos territoriales propios, mientras que han proliferado demasiadas ofertas similares, poco innovadoras y escasamente complementarias entre sí en la mayoría de los destinos. Así mismo, la oferta de alojamiento y de servicios complementarios todavía suele ser poco competitiva en muchos casos e insuficientemente adaptada a las exigencias de los demandantes específicos de este subsector turístico (idiomas, flexibilidad horaria, servicios especializados o incluso básicos, como el de alquiler de bicicletas, guías de montaña o servicio de

5 Todos los destinos tradicionales de montaña y de deportes blancos en España se enfrentan a los problemas de las temporadas de invierno, de mala climatología y pérdida de ocupación, visitantes y rentabilidad o de insuficiencia para rentabilizar las estaciones, por lo que han debido reorientarse y cambiar sus estrategias de producto, cada vez más centradas en verano y otoño. 
Figura 3. Distribución de la oferta promocionada de turismo activo en España según el tipo de actividad

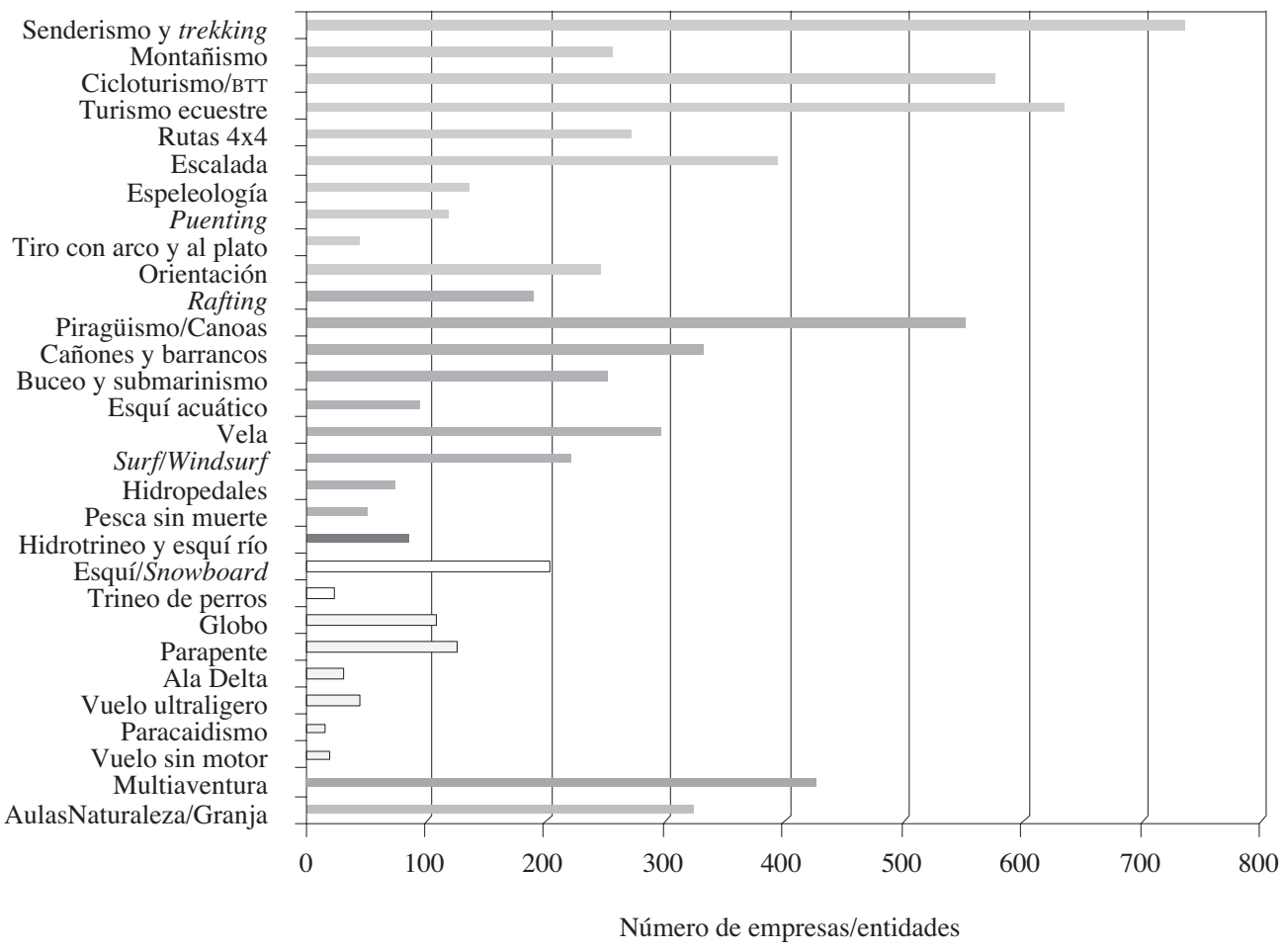

Fuente: Base de datos del Plan de Impulso de Turismo de Naturaleza (Antar-Ecotono, 2004); Estudio de producto de turismo activo en España (Secretaría General de Turismo, 2006); Guías Fitur Active 2007-2010 y base de datos propia con información de registros oficiales de Turismo CC. AA. y portales especializados de Internet. Elaboración propia. (N=1806).

guarda de caballos). Y no hemos de olvidar tampoco algunos problemas en materia de infraestructuras y equipamientos de soporte de la actividad, como la insuficiente señalización de recursos, rutas y puntos de práctica, o las precarias comunicaciones internas en no pocos destinos rurales y de montaña (red local y secundaria de carreteras).

Por su parte, la comercialización se ve afectada por la ausencia de departamentos comerciales en la mayoría de las empresas, la falta de unidad de acción de los productores finales sobre necesidades comerciales, su deficiente inserción en la oferta turística reglada y comercial de otros subsectores turísticos, y el escaso número de agencias e intermediarios especializados en la comercialización. A pe- sar de estas deficiencias, cabe destacar el alto interés de los productores por la comercialización directa por canales tecnológicos, además de la existencia de algunas ferias nacionales e internacionales de turismo de naturaleza.

En cuanto a la promoción, se detectan aún deficiencias, como el bajo reconocimiento y poca notoriedad de España en los mercados emisores internacionales como turismo de naturaleza y activo, exceptuando el turismo náutico o el golf, además de la presencia abrumadora de la oferta de sol y playa y de turismo cultural, difíciles de modificar a corto plazo.

No obstante, en los últimos años han proliferado diversas iniciativas conjuntas y ambiciosas de promoción del turismo activo por 
parte del Estado, muchas CC. AA. y grupos de desarrollo rural (Red de Vías Verdes, Camino de Santiago, marcas "España Verde" y "Pirineos", Red de Estaciones Náuticas, tanto litorales como de interior, proyectos de pesca-turismo, Estaciones de Vuelo Libre, centros BTT, etc.), que han dado algunos resultados positivos. Este también es el caso de los clubes de producto que integran ofertas de turismo activo en la naturaleza, y de algunas acciones promocionales más segmentadas y orientadas específicamente a este subsector turístico y de ocio, puestas en marcha por la Secretaría de Estado de Turismo (Cano, 2006).

\section{Contextualización geográfica y distribución regional del turismo activo en España}

En los últimos treinta años, la práctica físico-deportiva entre la población española comprendida entre los 15 y 65 años ha experimentado un crecimiento importante de unos 20 puntos porcentuales hasta llegar a un $45 \%$ en 2010 (frente a solo un $25 \%$ en 1980) ${ }^{6}$. Paralelamente, los deportes practicados al aire libre en espacios naturales, rurales y litorales también se han convertido en España en un fenómeno cada vez más cotidiano y habitual, y en una forma privilegiada de ocio y turismo para sectores relativamente amplios de la población. La última Encuesta sobre hábitos deportivos de los españoles (CIS, 2010) parece confirmar la estabilidad de esta tendencia y el incremento del número absoluto de practicantes de deportes en la naturaleza, de manera que $44,9 \%$ de quienes practican algún deporte lo hace habitualmente en lugares abiertos o en el medio natural, tratándose principalmente de un segmento demográfico de origen

6 Datos de la última Encuesta sobre los hábitos deportivos en España (2010) realizada por el Centro de Investigaciones Sociológicas (CIS) con la financiación del Consejo Superior de Deportes (Presidencia del Gobierno). urbano y mayoritariamente integrado por jóvenes, varones y de posición media-alta o alta. También se resalta que $15,1 \%$ de los practicantes de actividades físico-deportivas entre 15 y 74 años -obviamente con mejores condiciones físicas y un perfil psicosocial específico-realiza algún deporte de aventura en la naturaleza, sobre todo de carácter terrestre (77\% del total), como la bicicleta de montaña, el trekking, la escalada y el montañismo.

Esta realidad se constata igualmente con las estadísticas disponibles que hemos explotado específicamente y que apuntan a un fenómeno principalmente de carácter doméstico o de turismo de interior, procedente sobre todo de las áreas urbanas y particularmente de núcleos de más de 50000 habitantes relativamente próximos al destino y normalmente en la misma comunidad autónoma o en las limítrofes. No obstante, el movimiento internacional ha crecido en los últimos años, particularmente en destinos especializados (surf y kite surf en Tarifa, barranquismo en la sierra de Guara, deportes náuticos en Baleares y Valencia, descensos fluviales en Asturias, etc.), extendiéndose con fuerza por las zonas costeras.

Las actividades con mayor nivel de frecuentación son, sin duda, el senderismo, los paseos por el campo y el excursionismo, por tratarse de prácticas realizadas al aire libre, de manera autoguiada, de poca dificultad y baja exigencia física, y por estar muy potenciadas por las administraciones públicas (acondicionamiento de senderos señalizados, publicación de folletos y topoguías, organización de visitas guiadas gratuitas, habilitación de numerosos senderos GR, PR y SL, etc.). Otras prácticas bastante extendidas son la bicicleta todoterreno (BTT o mountain bike) y el cicloturismo; al respecto se destacan, en este sentido, los centros BTT/FCC que, introducidos por la influencia de Francia, están proliferando en Cataluña, el País Vasco y la Comunidad Valenciana, particularmente, y 
que se han extendido a otras regiones; también se destaca el programa "Vías Verdes", fomentado por el antiguo Ministerio de Medio Ambiente, con $1600 \mathrm{~km}$ y unas 65 vías en uso actualmente. Así mismo, el turismo ecuestre es otra práctica muy extendida que se apoya en la amplia red de vías pecuarias y caminos rurales y forestales existentes, aunque se trata, como contrapunto, de una actividad muy restringida en el ámbito de los espacios protegidos, $\mathrm{y}$ sin apenas itinerarios adecuados y equipados para su disfrute. Las actividades terrestres tienen un predominio abrumador (alrededor de un $75 \%$ ) pese a la diversificación progresiva a favor de las actividades acuáticas y aéreas que viene detectándose en la última década.

En las dos últimas décadas se ha experimentado en España una amplia difusión y extensión geográfica de las empresas y actividades de turismo activo. Si a finales de los años ochenta este segmento estaba vinculado fundamentalmente a los espacios acuáticos fluviales y de montaña del Pirineo catalán y oscense por influencia de los usuarios franceses (Lacosta, 2002), en la actualidad todas las comunidades autónomas y numerosos espacios de ocio cuentan con una oferta nada desdeñable (Lacosta, 2001 e IGN, 2008). Hay que señalar, en este sentido, que los espacios que configuran la territorialización de las prácticas de deportes de naturaleza son de límites imprecisos, de densidades turísticas difuminadas, y la distribución de la oferta presenta un carácter eminentemente "disperso" o "difuso" (zonal), de pequeña escala, frente al carácter más "concentrado" ("puntual" o "lineal") del turismo litoral y urbano, a la vez que se apoya en estrategias de desarrollo turístico más "artesanales" frente a las "masivas", seguidas en muchos puntos de la geografía española (destinos de sol y playa, grandes estaciones de esquí, ciudades patrimoniales...).
Muchas empresas buscan una localización cercana al cliente potencial y no tanto al ámbito geográfico donde se desarrollan las actividades, siendo el caso antológico de las aglomeraciones urbanas de Madrid, Valencia, Barcelona o Sevilla, entre otros. Pero, en general, tanto en los espacios rurales y naturales de interior como en el litoral, las empresas son bastante ubiquistas en relación con la proximidad de los espacios y equipamientos aptos para la práctica de las actividades: ríos, embalses, estaciones de montaña, simas y cuevas, costa, paredes rocosas, vías pecuarias, vías verdes y rutas de senderismo, puertos deportivos, etc. De esta manera, aparecen ejes de localización tan importantes como los tramos altos y las cabeceras de los cauces fluviales en zonas de montaña (cuenca del Tajo y afluentes de las estribaciones del Sistema Central, cuenca del Ebro en los afluentes del Alto Pirineo, embalses ubicados en zonas de montaña media y en cuencas como la del Guadiana y el Júcar, ríos de los picos de Europa, como el Sella y el Cares, y cursos altos de los ríos del Pirineo catalán y aragonés), algunas islas con espacios protegidos de grandes potencialidades como La Palma o Menorca, así como en el entorno de los parques nacionales y naturales, pese a las numerosas limitaciones que se fijan para los deportes de naturaleza en sus instrumentos de planificación y ordenación de usos. En general, son los ámbitos montañosos los mayores receptores de la oferta de actividades al concentrar un importante número de recursos naturales y paisajes atractivos que sirven de soporte y de cualificación de estas, además de ser los ámbitos más idóneos para la creación de senderos y equipamientos recreativos de uso público, como ocurre con los senderos GR (más de $50 \mathrm{~km}$ ), que conforman, por ejemplo, una red muy densa en el Pirineo, Cataluña o el País Vasco, y dibujan grandes ejes en el resto del país, como el Camino de Santiago (GR 65) o la Ruta de la Plata (GR 100). 
Figura 4. Empresas de turismo activo inscritas en los Registros Oficiales de Turismo de las comunidades autónomas de España (2014)

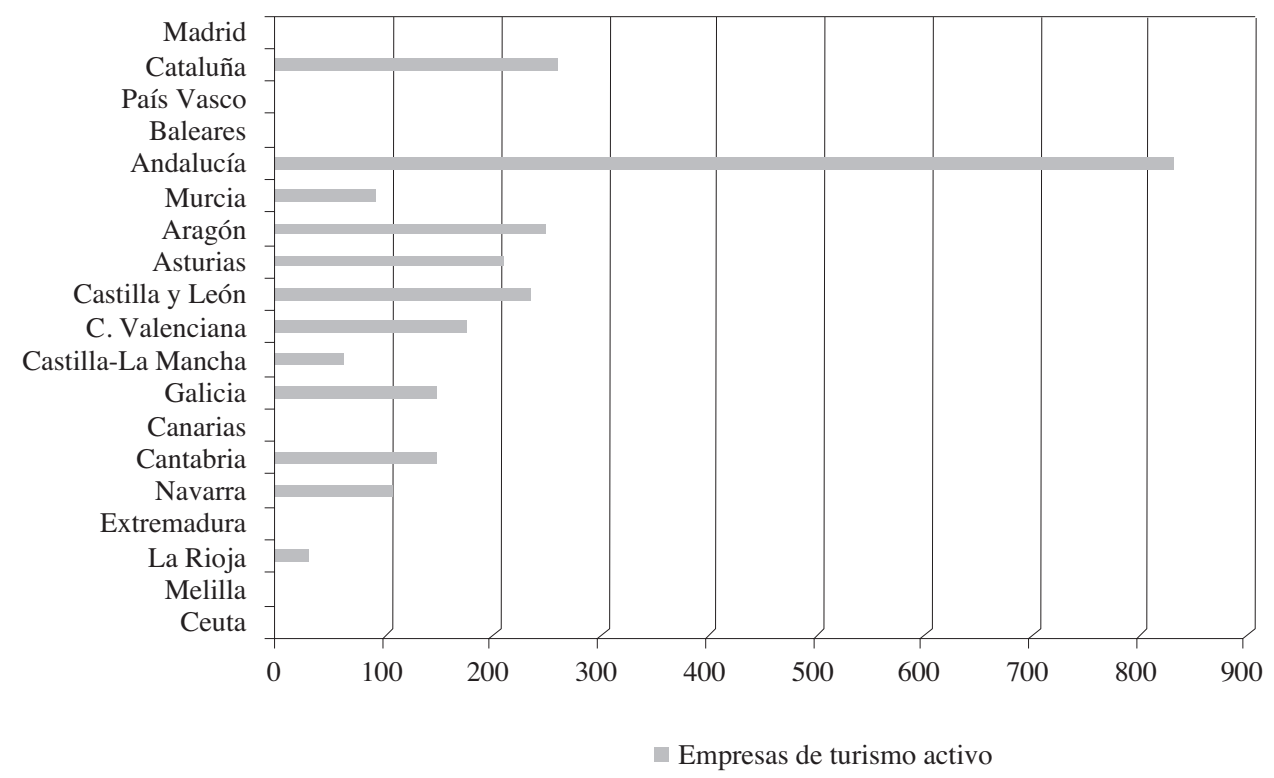

Fuente: Registros Oficiales de Establecimientos y Empresas Turística de las CC. AA. españolas con regulación del turismo activo (2014). Elaboración propia (N=2.578).

La consulta de los Registros Oficiales de Turismo de las CC. AA. que tienen regulado el turismo activo y cuyos datos hemos reflejado en la figura 4, complementada con la información obtenida sobre oferta promocionada en portales especializados de Internet y ferias especializadas de turismo -ya que aquellos no cubren la información de todo el territorio nacional y presentan no pocas deficiencias- nos han permitido confeccionar una base de datos específica y actualizada para aproximarnos más fielmente a su distribución regional, distinguiendo entre la oferta comercial convencional, la de intermediarios y la generada por clubes, asociaciones deportivas y algunas entidades públicas (figura 5). Las comunidades de Madrid y Cataluña se venían aglutinando, hasta hace relativamente pocos años, en torno al $24 \%$ de la oferta nacional, mientras que los territorios de la Cornisa Cantábrica y la "España Verde" (País Vasco, Asturias, Cantabria y Galicia) representaban casi otro $24 \%$, lo que confirmaba su mayor experiencia en la comercialización de vacaciones activas en la naturaleza (Rivera, 2009). No obstante, estas cifras relativas han bajado hasta el $14 \%$ y el $21 \%$ respectivamente, ante la emergencia y extensificación territorial de estas prácticas por todo el territorio nacional. De hecho, Andalucía es hoy por hoy la región que destaca en el ranking de la oferta de turismo activo en España, tanto en cifras absolutas como relativas (más de 800 empresas y alrededor de un $27 \%$ del total nacional) gracias a su enorme variedad y cantidad de recursos territoriales turísticos, que sirven de soporte tanto a actividades aéreas como terrestres y acuáticas, de interior, de zonas rurales, montañosas y de litoral, así como a su red extensa de espacios naturales protegidos. No en vano, también estamos hablando de la comunidad autónoma española de mayor extensión geográfica, después de Castilla y León (territorio exclusivamente de interior), con un total de $87599 \mathrm{~km}^{2}$ que suponen el $17,3 \%$ del territorio nacional. 
Figura 5. Organizaciones que ofertan en España actividades de turismo activo y deportivo en la naturaleza según comunidades autónomas

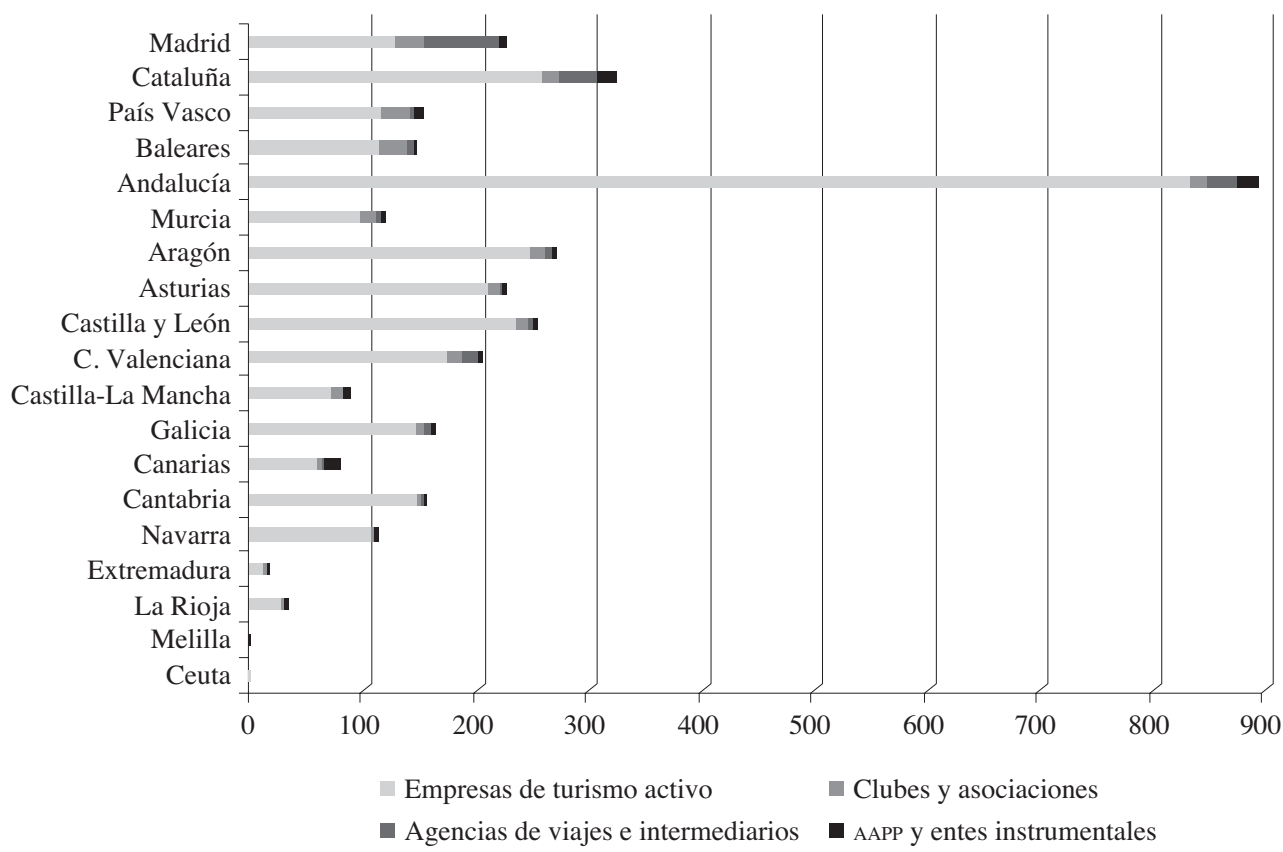

Fuente: Base de datos Plan de Impulso de Turismo de Naturaleza (Antar-Ecotono, 2004); Estudio de producto de turismo activo en España (Antar-Secretaría General de Turismo, 2006), Guías Fitur Active 2007-2010 (Fitur-Turespaña), base de datos propia oferta Internet y Registros Oficiales de Turismo CC. AA. Elaboración propia $(\mathrm{N}=3.510)$.

Destacan también en cifras absolutas las comunidades autónomas de Aragón, con más de un $8 \%$, por su importancia en oferta de actividades de montañismo, descenso de cañones y barrancos, y por sus deportes acuáticos fluviales y de nieve; Castilla y León, con más de un $7 \%$ de la oferta nacional, es el territorio de mayor extensión geográfica de España; y las comunidades autónomas con amplio litoral de Valencia y Baleares, que cuentan con importantes flujos turísticos anuales, un fuerte desarrollo de los deportes náuticos y una promoción amplia de deportes de naturaleza, como el senderismo, el cicloturismo y las excursiones a caballo.

Si en relación con la oferta, Andalucía es en la actualidad la región con mayor número de empresas de turismo activo, también en lo que respecta a la demanda se encuentra a la cabeza del ranking de destinos nacionales en número total de viajes de españoles que incluyen la práctica de deportes al aire libre, terrestres, de bajas o moderadas exigencias físicas, como es el caso del senderismo, el cicloturismo, los paseos por el campo o las rutas a caballo, de manera que representan en esta comunidad más del $15 \%$ del total de viajes nacionales que incorporan estas prácticas como actividades para practicar durante las vacaciones. En este sentido, los datos del movimiento turístico interior de los últimos años vienen a confirmar el desplazamiento del primer puesto en el ranking autonómico de comunidades como Cataluña, que se ubica por encima de otros territorios bien posicionados, como la Comunidad Valenciana, Castilla y León y Aragón.

No obstante, la posición de los deportes al aire libre como actividad vacacional de importante motivación en los viajes a esta comunidad 
es aún sensiblemente inferior a la alcanzada por los territorios comprendidos en la denominada "España Verde" y otros territorios del norte del país con importantes áreas montañosas, como es el caso de Asturias, el País Vasco, Navarra, Aragón, Cataluña, algunas zonas del litoral mediterráneo (Valencia y Baleares) y las Islas Canarias, claramente más especializados en estas actividades y con un mejor nivel de posicionamiento tanto en los mercados nacionales como internacionales, si bien se encuentra prácticamente al mismo nivel que el País Vasco, Cantabria y Castilla-La Mancha. Si nos atenemos a su significación territorial (turistas practicantes/ $\mathrm{km}^{2} /$ CC. AA.), las CC. AA. de Valencia, Cataluña, Cantabria, Asturias, Madrid y las Islas Baleares acaparan el protagonismo (figura 6).

Son precisamente también las CC. AA. limítrofes entre sí las que se comparten los viajes activos en mayor medida, caso de las que conforman la España Verde, lo que parece reforzar la idea de que no es solo la proximidad geográfica, sino también la similitud de los territorios de práctica (paisajística, climática, cultural, natural...) la que atrae la demanda en estas zonas. Las actuaciones promocionales de Turespaña como la marca "España Verde" o "Pirineos" pueden reforzar estas sinergias, pero también obligan a buscar la diferenciación dentro de esa imagen global.

En cuanto al peso del turismo de origen nacional motivado por los deportes de aventura y riesgo, se destacan las comunidades autónomas de mayor trayectoria en la oferta y comercialización de estas actividades, como Aragón (15 a 25\% según años), Cataluña (entre 12 y 16\%), Galicia, Cantabria y CastillaLeón, donde la introducción de estos deportes orientados a turistas y deportistas más especializados y de mayor capacitación técnica y físico-motriz ha sido más antigua e intensa. Así mismo, este tipo de actividades deportivas tiene escasa significación relativa aún en comunidades del interior y sur del país, como las dos Castillas, Extremadura o Andalucía, muy a distancia aun de otras comunidades autónomas, como Aragón, Galicia, Cantabria, Cataluña, Navarra, Asturias, Canarias y Baleares, donde alcanza también una mayor incidencia territorial si relacionamos el número de practicantes con su superficie territorial (figura 7).

Figura 6. Turistas nacionales de deportes al aire libre suaves por $\mathrm{km}^{2}$ según CC.AA. (2010)

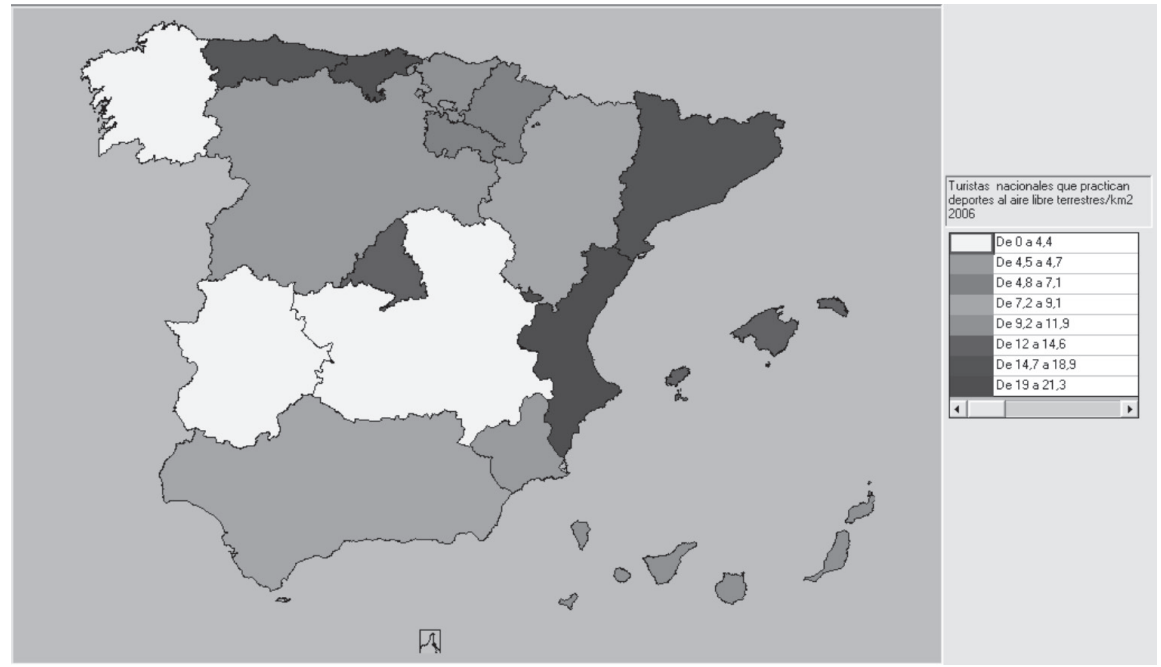

Fuente: Instituto Geográfico Nacional e Instituto de Estudios Turísticos (Familitur 2010). Elaboración propia. 
Figura 7. Turistas nacionales que practican deportes de aventura y riesgo por $\mathrm{km}^{2}$ según CC. AA. (*)

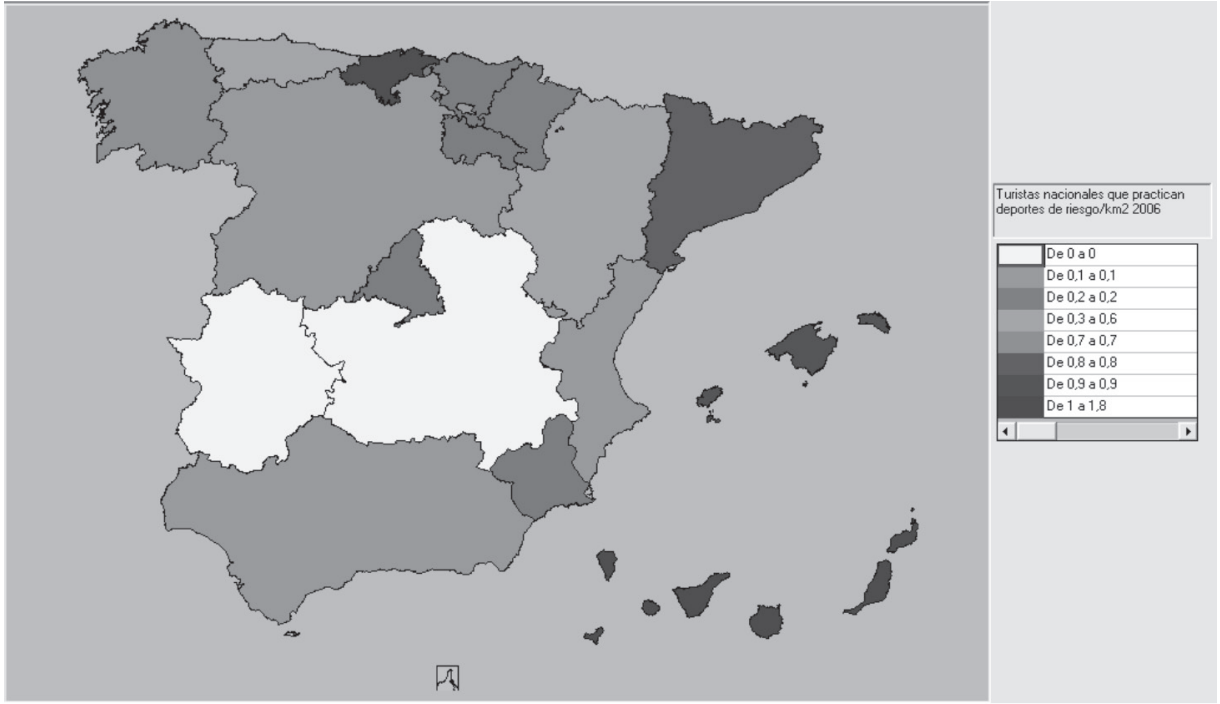

Fuente: Instituto Geográfico Nacional e Instituto de Estudios Turísticos (Familitur, 2010). Elaboración propia.

(*) No se representan los resultados de las comunidades autónomas de Murcia, el País Vasco, La Rioja y Madrid, por ser la base muestral insuficiente para la obtención de resultados significativos.

\section{Tendencias recientes de la oferta comercial de turismo activo}

En las dos últimas décadas se ha percibido un proceso prácticamente continuo de diversificación de las prácticas físico-deportivas y de ocio activo en la naturaleza. Como hemos apuntado antes, a partir de los años ochenta y noventa, paralelamente a la utilización de nuevos espacios de ocio (como senderos adaptados y señalizados, vías y corredores verdes, circuitos al aire libre para BTT, espacios forestales de sierras prelitorales, paredes rocosas, altas cumbres, zonas de litoral con mucho viento y oleaje, pantanos y embalses de interior, fondos marinos, zonas áridas para deportes de motor, etc.) también es perceptible el avance de las prácticas individualizadas frente a las actividades colectivas y la búsqueda de espacios naturales de práctica (lugares abiertos, más insólitos y vírgenes, difíciles o propicios a la invención de "nuevas aventuras"), con una cierta perspectiva más o menos ecológica o de contacto directo con la naturaleza. Por último, es de destacar el proceso de "democratización” y extensión de estas prácticas entre diversos grupos sociales y motivacionales (jóvenes y mayores, deportistas federados y de competición, y simples excursionistas o turistas, practicantes especializados y familias con niños, turistas deportivos y de naturaleza de diferentes perfiles sociodemográficos).

Entre los productos y ofertas novedosos y de cierto impacto cualificador, promocional y mediático en muchos destinos, hemos de considerar los siguientes:

1. Los productos de ecoturismo que conllevan la realización de alguna actividad de ocio activo o de carácter físico-deportivo, aunque solo sea como resultado del desplazamiento por medios no motores en el medio natural. De entre ellos se destaca el turismo ornitológico, tan vinculado 
al senderismo interpretativo y de cierto predicamento entre el turismo extranjero de naturaleza, procedente sobre todo del Reino Unido y Alemania, aun cuando sigue siendo una modalidad turística muy minoritaria (Fernández, 2007).

\section{Las actividades de educación ambiental} y el agroturismo (granjas escuela, aulas de naturaleza y aulas del mar, talleres de educación ambiental), aunque orientadas prioritariamente al segmento poblacional juvenil e infantil y a grupos escolares, por lo que están muy poco integradas en la oferta turística local y en los circuitos de comercialización convencionales (Rivera, 2009).

3. El senderismo interpretativo por los espacios naturales protegidos, aunque no se conforme en la mayoría de los casos como un producto turístico comercializado, sino de práctica autónoma y libre sin contratación de servicios turísticos de guía en destino. De hecho, ni tan siquiera en el entorno de equipamientos de relevancia, como las Vías Verdes, Corredores Verdes, senderos GR o rutas de parques naturales, la mayor parte de los usuarios acuden a empresas especializadas.

\section{Parques temáticos de naturaleza y par-} ques periurbanos y litorales, a modo de adecuaciones recreativas con equipamientos blandos, una oferta específica turístico-recreativa, de esparcimiento y educación ambiental basada en el aprovechamiento de los recursos naturales del entorno y en una serie de instalaciones y circuitos para la práctica de actividades físico-deportivas y de ocio activo de naturaleza que introducen la "tematización" como argumento de redefinición de la oferta turística de naturaleza, pero sin llegar a modificar de manera sensible el espacio natural que le sirve de soporte. Presentan un carácter desestacionaliza- dor cuando se ofertan como un producto comercial de ciclo anual basado en la existencia de una importante oferta de actividades y alojamiento dirigido a escolares y grupos específicos, como es el caso del Parque Dunar de Matalascañas en el entorno del Parque Nacional de Doñana.

5. Los parques de aventura al aire libre, también conocidos como "parques acrobáticos forestales", introducidos en España en la primera década de este siglo por influencia de los parques de aventura de Francia, país con mayor número de instalaciones de este tipo en Europa (Franc, 2005). Estos parques están integrados por equipamientos blandos y adaptados para la práctica de actividades físico-deportivas por parte de públicos amplios (tirolinas, pasos de gigante, saltos de trazan, puentes basculantes, pasarelas colgantes, cuerdas y lianas, rocódromos artificiales o naturales, etc.). Para ello utilizan diversos materiales de bajo impacto ambiental en zonas boscosas y forestales donde los árboles constituyen un elemento básico de sujeción e instalación de dichos equipamientos. Suelen contar en algunos casos con diversos circuitos de torres de estructura de madera con seguridad pasiva para niños o activa para toda la familia, además de puentes fijos y puentes colgantes también de madera y cuerda para efectuar diversos recorridos aéreos, pruebas de habilidad y actividades físico-deportivas. Desde hace varios años, parte de esta oferta (unos veinte ecoparques) está agrupada en la Asociación Española de Parques de Aventura (AEPA) y representada por dicha Asociación, si bien hemos podido censar en España alrededor de sesenta, todos ellos de aparición en la última década.

\section{Otros complejos recreativos de multia-} ventura se localizan preferentemente en entornos periurbanos de grandes ciudades para garantizar -sobre todo en fines de 
semana y días festivos- una importante afluencia de público de perfiles variados, tales como grupos y campamentos escolares, incentivos de empresa, familias con niños, concentraciones de clubes deportivos, actividades de team building y outdoor training, grupos de amigos, fiestas y celebraciones familiares, etc. Estos complejos facilitan la experimentación de situaciones de "aventura controlada" mediante equipamientos homologados y estructuras artificiales en la naturaleza, de amplia seguridad y para públicos amplios, turísticos y de demanda recreativa de proximidad, lo que los convierte en instalaciones versátiles durante buena parte del año, que introducen un factor beneficioso de desestacionalización de la demanda turística local.

7. Actividades físico-deportivas de reciente aparición o conformación turísticorecreativa, pero de importante difusión, entre las que encontramos: a) actividades terrestres como el paintball, el skatewind o el nording walking. Las actividades de paintball se ofertan tanto en complejos al aire libre debidamente adaptados para su práctica en plena naturaleza con actividades complementarias (barbacoas, catering, etc.) como en recintos cerrados (campos indoor), generalmente en el entorno cercano de grandes ciudades y áreas metropolitanas. Las actividades como el positronic o skate-wind-que cuentan ya con el respaldo de federaciones de vela españolas, el Consorcio Mundo Vela o la Profesional Windsurfing Association- se han desarrollado y patentado en España, y otras como el nordic walking han sido importadas del centro o norte de Europa. b) Actividades acuáticas y subacuáticas en sus diferentes modalidades, tanto competitivas (concursos de pesca submarina, orientación subacuática, natación con aletas, apnea, fotografía submarina, etc.) como recreativas y científicas (juegos subacuáticos, como búsqueda del tesoro, kayak de mar, hockey, biología y arqueología submarinas, snorkeling, scuba diving, etc.), formativas (cursos de buceo deportivo en sus distintos niveles) o de otro tipo (organización de jornadas, concentraciones, etc.). En los últimos años se ha registrado una progresiva introducción del buceo deportivo en los circuitos profesionales de comercialización turística $y$, en este sentido, ha de destacarse el producto "bautismo de buceo", consistente en alguna clase teórica y una inmersión en mar abierto a lo largo de un día. La oferta, en cualquier caso, está siendo capitalizada mediante comercialización directa para formación de técnicos y aficionados, si bien falta una adecuada vertebración de estos centros con otros agentes turísticos y deportivos y con otros subsectores de actividad turística. Igualmente han aparecido en los últimos años algunas adecuaciones de espacios acuáticos y equipamientos para la práctica del esquí acuático tanto en aguas continentales de interior como en las litorales, si bien todavía es escasa la oferta estructurada comercialmente. Y c) actividades aéreas, en las que aparte de algunas actividades de mayor tradición, como el globo aerostático, han surgido otras -antes reducidas al ámbito exclusivamente deportivo- que han acabado integrándose en la oferta turística, como el parapente, ala delta, vuelo ULM, paracaidismo, paramotor y paratrike.

8. Espacios deportivo-turísticos generados y acondicionados por la intervención de las administraciones públicas y de agentes privados, a veces con usos mixtos no exclusivamente turísticos, como aeródromos y estaciones de vuelo libre y centros BTT (figura 8), que responden a nuevas lógicas de planificación y programación público-privadas en el fomento de las prácticas físico-deportivas con orientación turístico-recreativa, mediante 
modelos descentralizados y "proyectos de territorio" locales y regionales en los que se intenta integrar a los agentes deportivos y turísticos. Estos espacios, a su vez, incluyen acciones de señalización, acogida y atención de practicantes, información y promoción, avituallamiento y servicios auxiliares, etc., estando planificados incluso en los instrumentos de ordenación urbanística y territorial de los municipios donde se ubican e incluidos en las estrategias de desarrollo rural y sostenible de carácter local, comarcal o regional.

La incidencia socioeconómica del desarrollo de nuevas actividades y productos no puede valorarse meramente en términos cuantitati- vos, pues ciertamente no representan todavía más que un subsector emergente y muy modesto relativamente del volumen total de la oferta y la demanda turística; debe valorarse en términos cualitativos, por lo que supone de diversificación de actividades económicas en entornos rurales o periurbanos, la incorporación de población joven en las nuevas empresas de turismo activo, la especialización y diferenciación productiva de algunos destinos o la recualificación e imagen de marca que aportan en otros casos, la dinamización social y económica general o la mejora de infraestructuras y equipamientos locales de uso general también por las propias comunidades locales.

Figura 8. Principales centros BTT de bicicleta de montaña en España (2014)

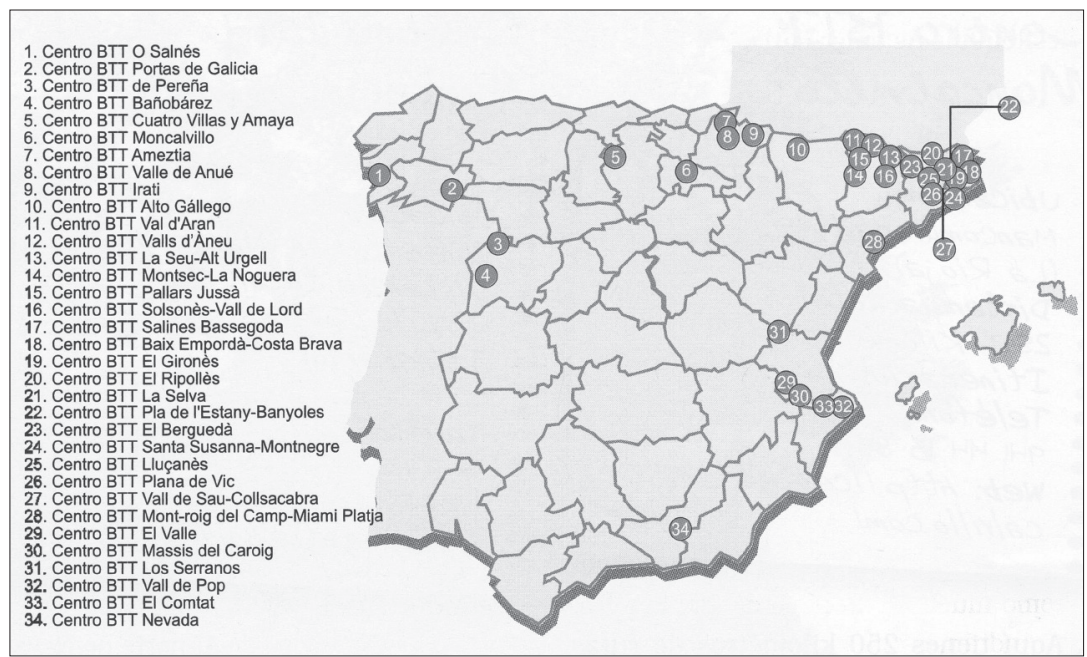

Fuente: Portales especializados de Internet, administraciones turísticas regionales y clubes deportivos (2013). Elaboración propia.

Así mismo, el desarrollo de estos nuevos o readaptados productos de turismo deportivo en la naturaleza ha tenido unos efectos añadidos en los destinos, los cuales podemos resumir así:

1. La desestacionalización de los destinos, la mejora de la conexión turística y las sinergias complementarias entre las áreas del interior, las rurales y las periurbanas, así como también las áreas costeras en no pocos casos.

2. La mejora de la experiencia, la satisfacción de los visitantes y la señalización de la demanda, con lo que ello representa de incremento en gasto turístico y la estancia media, aunque no siempre sea lo suficien- 
te como para frenar su caída continua en algunas zonas.

3. La mejora de la imagen de los destinos turísticos. Aunque la práctica del turismo activo atraiga por sí misma a un número todavía limitado de usuarios, la existencia de una variedad de ofertas "activas" se convierte en un elemento diferencial y competitivo con relación a otros destinos alternativos (Tur, 1999), y si el esfuerzo se centra en el desarrollo de una determinada oferta de turismo activo o la captación de un determinado segmento de demanda, puede conseguirse el objetivo de la diferenciación y singularización del destino.

4. La creación de nuevas expectativas de negocio, aun cuando muchas veces se basen en productos escasamente estructurados en el ámbito global, pero que son importantes desde el punto de vista de la oferta complementaria de ocio y tiempo libre.

Este nuevo escenario encaja, por lo demás, con los nuevos planteamientos teóricos que utilizan el término "neofordismo" para referirse a la situación actual que vive el sector turístico, sobre todo en los espacios litorales y urbanos, pero también en los rurales y de interior. Con este término se quiere reflejar que nos encontramos ante una etapa un tanto contradictoria (Antón, 2004), en la que coexisten prácticas propias del modelo turístico tradicional imperante desde la década de los años sesenta del siglo pasado -que ahora se intensifican o se reformulan según los casos-, junto con nuevas tendencias y dinámicas que apuntan hacia cambios significativos en relación con el funcionamiento de la actividad turística (posfordismo), en los que los productos y espacios de ocio ligados al turismo deportivo de naturaleza están adquiriendo, sin duda, un papel muy importante en España.

\section{Conclusiones}

En los últimos años, y específicamente a partir de 2010, parece confirmarse una recuperación significativa tanto de oferta como de demanda interna del subsector turístico-recreativo de los deportes en la naturaleza en España, como reflejan las cifras de la última Encuesta de hábitos deportivos del Centro de Investigaciones Sociológicas (CIS), Familitur (IET) y el Consejo Superior de Deportes, algunos registros de turismo autonómicos y los portales especializados de promoción de estas actividades comerciales en Internet.

También los últimos años han sido fructíferos en cuanto a medidas legislativas de ámbito europeo, nacional y autonómico, las cuales han favorecido el desarrollo de la oferta empresarial de turismo activo en cuanto a supresión de algunas trabas y condicionamientos que estaban constriñendo a este subsector turístico, de manera que se está notando el afloramiento de empresas anteriormente clandestinas, así como la nueva creación de otras muchas de manera significativa, lo que puede conducir a la normalización de esta oferta y a su consolidación definitiva en los próximos años. El interés por este subsector en las nuevas legislaciones de turismo de las CC. AA. es también un hecho para destacar, de igual manera que lo es el desarrollo de una norma " $Q$ " de calidad turística específica para el turismo activo -puesta en marcha en 2010 por el Instituto para la Calidad Turística Española (ICTE)-, así como una norma UNE IND, el incremento de las acciones promocionales por parte del Estado y las CC.AA. destinadas a este segmento de demanda, y los avances en la vertebración del tejido empresarial de turismo activo mediante la ANETA y otras asociaciones regionales.

Pero, pese a la consolidación progresiva de las prácticas físico-deportivas en la naturaleza 
dentro de la oferta turística de muchos destinos españoles, no se puede hablar aún de un segmento turístico plenamente consolidado (Rivera, 2010), y las cifras de usuarios solo son relativamente significativas cuando consideramos estas actividades en el marco de la oferta turístico-recreativa complementaria y no como principal motivación de los desplazamientos a los espacios rurales, litorales y naturales. Por otra parte, la concentración geográfica de la oferta y la demanda, sobre todo en lo que se refiere a los deportes de aventura y más especializados, sigue siendo palpable en lo autonómico, lo que no quita para que reconozcamos el importante papel que desempeñan las actividades de turismo activo como elementos diferenciadores para muchos destinos, tanto emergentes como tradicionales.

Aunque aún no llegamos obviamente al volumen de negocio y de demanda de otros países europeos, el aumento de las prácticas físico-deportivas en la naturaleza de la población española está generando un incremento de clientes de origen nacional que no se ha visto tan afectado por la crisis económica, al menos relativamente, respecto a otros subsectores turísticos, sobre todo en el ámbito de los deportes blandos, más económicos y de ejercicio libre, que no necesitan de intermediarios y de equipamiento sofisticado y que, además, se adaptan a todo tipo de público y aportan mucha satisfacción a los consumidores por tratarse de un buen instrumento de acercamiento y contacto con la naturaleza (senderismo, cicloturismo, turismo ecuestre, paseos por el campo...). Se trata, no obstante, de un subsector turístico y recreativo al que aún le queda un largo camino por recorrer por estar poco insertado en la oferta turística reglada y comercial, siendo aún pocas las agencias e intermediarios especializados en la comercialización de "vacaciones activas en la naturaleza", así como las infraestructuras y equipamientos adecuados y especializados para la práctica de muchos deportes al aire libre ${ }^{7}$.

La riqueza y variedad de los recursos naturales que sirven de soporte y cualificación de estas actividades en España, su amplia red de parques y reservas naturales, su situación geográfica, su configuración geomorfológica y sus especificidades climáticas están sirviendo de motor para el desarrollo de estas prácticas, cada vez más numerosas y diversificadas, a lo largo de todo el año. En este sentido, la evolución de las prácticas deportivas está abriendo continuamente nuevos mercados y públicos potenciales, apoyados en valores sociales y hábitos de consumo bien definidos: ejercicio físico, salud, contacto interactivo y directo con la naturaleza, autenticidad, calidad, diversidad de ofertas recreativas, aventura, y más recientemente seguridad y confort, con el desarrollo de ofertas adaptadas a todos los públicos y las vacaciones en familia. En un par de décadas han ido surgiendo multitud de nuevas submodalidades deportivo-recreativas que han ido acompañando, complementando o hasta sustituyendo a otras más antiguas y tradicionales: vía ferrata/escalada, kite surfl surf, orientación/geocaching, multiaventura/ parques acrobáticos forestales y de aventura "suave", esquí/snowboard y freestyle de nieve, nordic walking, etc.

La consolidación progresiva de las prácticas físico-deportivas en la naturaleza en España apunta, en cualquier caso, a la configuración a medio plazo, aunque de manera lenta, de un nuevo segmento de demanda turística con personalidad propia, pero que conecta bien con otros turismos tradicionales, como viene sosteniendo la propia ANETA, que reciente-

7 Es significativa, por ejemplo, una reciente encuesta de la RACE que señala que el $80 \%$ de los ciclistas españoles considera que no existen buenas vías para la práctica del cicloturismo y de la bicicleta recreativa, y las que existen presentan, en la mayoría de las ocasiones, déficit de mantenimiento, limpieza y equipamientos de apoyo. 
mente, a finales de 2014, ha organizado su III Congreso Nacional de Turismo Activo en Cabra (Córdoba). Esta tendencia se está ya constatando, de hecho, en el conjunto de Europa, como ha puesto de manifiesto una de las últimas encuestas de World Travel Monitor para la Feria ITB de Berlín, que ha registrado un incremento del turismo deportivo al aire libre en los mercados emisores europeos de dos dígitos en los últimos cinco años, superando incluso a un segmento de tanto crecimiento reciente como el turismo de cruceros (IPK International, 2010).

Para que estas previsiones se cumplan y el turismo deportivo en la naturaleza sea mucho más que una oferta meramente complementaria o residual de los turismos temáticos tradicionales, han de superarse aún muchos problemas, como el importante intrusismo existente por parte de empresas ilegales, la falta de homogeneidad y adecuación a la realidad del sector de las regulaciones existentes de la oferta en las CC. AA., las trabas todavía existentes que impiden una efectiva unidad de mercado del turismo activo, la debilidad y dispersión del tejido empresarial, las fuertes restricciones de uso -no siempre meditadas y razonadas- en los espacios naturales protegidos (Rivera, 2015), la ausencia de marcas y certificaciones de calidad realmente aplicables a este subsector, o las deficiencias en materia de promoción, comercialización y formación técnica de monitores y directores de empresas de turismo activo. Hay que tener en cuenta, así mismo, como ya puso de manifiesto el Plan de Impulso del Turismo de Naturaleza en España, que aún no se tiene forjada una imagen de marca visible y consolidada como destino nacional de turismo deportivo de naturaleza (Antar Estrategias Creativas, 2006).

El desarrollo de estas prácticas recreativas y turísticas sigue necesitando también de una colaboración más estrecha entre el sector público y la iniciativa privada, una mayor promoción y tratamiento específico en las políticas turísticas regionales y estatales, una planificación sostenible adecuada por las características genuinas e implicaciones territoriales, medioambientales y socioeconómicas de estas actividades, así como también una mayor integración y sinergias con el resto de la oferta turística de los destinos. Lo cierto es que en España, las iniciativas públicoprivadas ligadas al fortalecimiento de estas actividades en el marco de proyectos específicos de desarrollo local han sido relativamente numerosas en la última década, especialmente en territorios y comarcas del interior, donde su interacción con el turismo cultural, rural y de naturaleza puede acaparar frutos importantes (Medina y Sánchez, 2005), además de generar una oferta de productos bien estructurados, amparados por marcas de calidad y destinos especializados de turismo deportivo bajo el prisma de la sostenibilidad, la diferenciación y la promoción específica, como es el caso de Cataluña (Cots, Roca, Baeza y Sallent, 2010). Pero lo cierto es que no han dejado de ser muchas veces proyectos aislados, de poco tamaño y relevancia a efectos demostrativos, echándose en falta la creación de redes de colaboración interempresarial, clubes de producto y ofertas más estructuradas con capacidad de penetración en el mercado.

Sin duda, estas últimas medidas son fundamentales para la estructuración del turismo activo como turismo de motivación específica conformado por productos especializados, integrados y más estandarizados, y no meramente como subproducto de los turismos genéricos. Para ello, las estrategias de comercialización también tienen que saber identificar canales eficientes de introducción en los mercados internacionales, de percepción y de diferenciación de las empresas de distintas características y niveles de oferta ante el cliente final, y de sostenibilidad y desestacionalización de las empresas: ofertas de multiaventura o "multiactividad"; prácticas de asociación comercial interem- 
presarial y con otros subsectores, como el de alojamiento; intermediación con entidades y agencias de viajes especializadas; captación de segmentos de demanda emergentes, como los incentivos y reuniones de empresa (team building, outdoor training); actividades de grupos escolares y juveniles, eventos lúdicos familiares, demanda urbana de proximidad o iniciación y formación deportiva. Y, por añadidura, la promoción turística institucional no puede seguir siendo tan inespecífica y excesivamente genérica y ha de considerar de manera más adecuada la oferta real existente, así como también conocer mejor el perfil de la demanda real y potencial, sobre todo la de origen extranjero, para conseguir un diseño y una promoción del producto final más efectivos.

\section{Bibliografía}

ANTAR Estrategias Creativas. (2006). Estudio para la creación del producto de turismo activo y comunicación del Plan de Impulso del Producto Turismo de Naturaleza en España, Madrid: Secretaría General de Turismo.

Antón, S. (2004). De los procesos de diversificación y cualificación a los productos turísticos emergentes. Cambios y oportunidades en la dinámica reciente del turismo litoral. Papeles de Economía Española, 102, 316-333.

Blanco, E. (2008). Turismo activo y la relación con la interpretación del patrimonio y la educación ambiental. En I Jornadas Internacionales de Educación Ambiental. Tenerife: Cabildo de Tenerife. Recuperado de http://www.jornadaeducacionambiental.org/talleres/index.html

Bourdeau, P. (1995). Le tourisme sportif de nature. Cahiers du CERAMAC, 73-88.

Cano, M. (2006). Las estrategias de promoción exterior del turismo deportivo y de naturaleza es- pañol del Instituto de Turismo de España. Estudios Turísticos, 169/170, 39-49.

Centro de Investigaciones Sociológicas (CIS). (2010). Encuesta sobre los hábitos deportivos en España 2010. Madrid: CIS/Consejo Superior de Deportes (CSD).

Chazaud, P. (2004). Management du tourisme et des loisisrs sportifs de pleine nature. Voiron: Presses Universitaires du Sport.

Cots, F., Roca, E., Baeza, L. y Sallent, O. (2010). Turismo activo y sostenibilidad en Cataluña: una valoración desde el sector privado. Estudios Turísticos, 183, 75-90.

De Juan, J. M. (2006). Turismo activo. En D. López y J. I. Pulido (Eds.), La actividad turística española en 2006 (pp. 659-670). Madrid: Centro de Estudios Ramón Areces y AECIT.

Fernández,A.et al.(2007).El turismo ornitológico en España como modalidad turística emergente. Organización interna de la actividad y caracterización de la demanda. Papers de Turisme, 42, 41-56.

Figuerola, M. (1986). Política de turismo. En L. Gámir (Coord.), Política económica de España. Tomo II (pp. 449-465). Madrid: Alianza Universidad.

Franc, T. (2005). Les parcs acrobatiques forestiers. Une activité en pleine expansion. Cahiers Espaces, 86, 81-83.

García, P. J. (2010). Turismo activo y medio ambiente: una implicación necesaria. Cuadernos de Turismo, 26, 153-176.

González, M. y Moscoso, D. (2006). Hacia un sistema deportivo integrado y sostenible: la interlocución y la prevención en el proceso de instauración del deporte en espacios naturales protegidos y las zonas rurales. Córdoba: Instituto de Estudios Sociales Avanzados de Andalucía.

Rev. Turismo y Sociedad, vol. XVI, enero-junio 2015, pp. 85-108 
González, A. (2008). Rasgos caracterizadores del turismo activo y turismo deportivo e importancia económico-social y estructural de nuevas formas emergentes. Acciónmotriz.com, 1, 1-24.

Granados, V. (1998). Nuevas formas de turismo: el turismo rural en Andalucía. Boletín Económico de Andalucía, 10, 35-50.

Granero, A. (2007). Las actividades físico-deportivas en la naturaleza y la industria turística. Revista Internacional de Medicina y Ciencias de la Actividad Física y el Deporte, 7(46), 111-127.

Instituto de Turismo de España. (2008). Turismo de montaña. Madrid: Turespaña.

IPK International.(2010). ITB World Travel Trends Report 2010-2011. Berlín: ITB Library, Messe Berlin $\mathrm{GmbH}$.

Instituto Geográfico Nacional (IGN). (2008). Turismo en espacios rurales y naturales. Madrid: Centro Nacional de Información Geográfica.

Lacosta, A. J. (2001). Aproximación al sector del turismo activo y de aventura en España. Implicaciones territoriales y distribución espacial. En Actas del XVII Congreso de la Asociación de Geógrafos Españoles (pp.358-364). Oviedo: Universidad de Oviedo, AGE y GE.

Lacosta, A. J. (2002). Los deportes de aventura y su incidencia en el desarrollo turístico de un espacio protegido: el Parque Natural de los Cañones de la Sierra de Guara (Huesca). En AA.VV., Turismo y transformaciones urbanas en el siglo XXI (pp. 235247). Almería: Universidad de Almería.

López, F. (1993). Modalidades turísticas y tipologías de espacios turísticos. Papers de Turisme, 11, p. 54

Mediavilla, L. (2007). La dinamización de los espacios naturales protegidos a través de las actividades físicas en el medio natural: análisis de los trece parques nacionales de España. En A. Miguel.
(Coord.), Desde la universidad deportiva de verano (pp. 463-491). Palencia: Patronato Municipal de Deportes.

Medina,F. y Sánchez, R. (2005). Actividad físicodeportiva, turismo y desarrollo local en España. Pasos. Revista de Turismo y Patrimonio Cultural, 3(1), 97-107.

Miguel, A. (1984). La demanda turística. Revista Situación, 1, 26-49.

Nasser, D. (1995). Deporte y turismo activo: una reflexión sociológica. En AA. VV., I Congreso de Turismo Rural y Turismo Activo (pp. 481-499). Ávila: Junta de Castilla-León.

Plata, N. (2006). El entorno jurídico de las nuevas tendencias deportivas, deporte de aventura, animación deportiva y ocio activo. Madrid: Dykinson.

Rivera, M. (2007). La emergencia del turismo y el ocio deportivo en la naturaleza en Andalucía y España: aproximación al estudio de su demanda reciente. En AA. VV. Turismo y Sociedad en Andalucía (pp. 51-84). Sevilla: Consejería de Turismo, Comercio y Deporte.

Rivera, M. (2009). Los Centros de Educación Ambiental y su inserción en la oferta turística y recreativa de los espacios naturales protegidos: una aproximación desde Andalucía. En XII Congreso Internacional de Turismo, Universidad y Empresa: Turismo y espacios naturales (pp. 337-368). Castellón: Universidad Jaume I y Tirant lo Blanch.

Rivera, M. (2010). Turismo activo en la naturaleza y espacios de ocio en Andalucía: aspectos territoriales, políticas públicas y estrategias de planificación. Sevilla: Consejería de Turismo, Comercio y Deporte.

Rivera, M. (2010). Turismo deportivo en la naturaleza. En D. López y J. I. Pulido (Edit.), La actividad turística española en 2009 (pp. 665-681). Jáen: Edit. Ramón Areces y AECIT. 
Rivera, M. (2011).Los espacios de ocio deportivo de naturaleza en destinos litorales: innovación espacial, nuevas prácticas y cualificación de sistemas turísticos en la costa andaluza. En D. López (Ed.), Renovación de destinos turísticos consolidados (pp. 701-741). Valencia: Universidad Jaume I de Castellón y Edit. Tirant lo Blanch.

Rivera, M. (2011). Deportes de naturaleza, turismo activo y nuevas estrategias de renovación y recualificación turística en la montaña de Sierra Nevada. En XII Coloquio de Geografía del Turismo, Ocio y Recreación (pp. 455-472). Madrid: AGE y Universidad de Carlos III.

Rivera,M.(2015). El tratamiento de las actividades de turismo activo en los instrumentos de planificación ambiental de los parques naturales andaluces. Revista de Estudios Regionales, 102, 52-69.

Rodríguez, P. (2006). La importancia del turismo deportivo en la naturaleza en España. Reflexiones y evidencias empíricas. En D. Moscoso y E. Moyano (Coord.), Deporte y desarrollo rural (pp. 181-194). Málaga: Instituto Andaluz del Deporte.

Sallent, O. (2006). Ocupación activa del tiempo de ocio. Hosteltur, marzo, 6-24.
Sánchez, M. I. (2006). Diversificación en la comercialización del turismo en espacios rurales y naturales: el outdoor training. En D. Blanquer (Dir.), VIII Congreso Internacional de Turismo, Universidad y Empresa. Turismo en Espacios Rurales (pp. 181-197). Valencia: Tirant lo Blanch y Universidad Jaume I de Castellón.

Tur, V. (1999). El turismo activo en Balears. Palma de Mallorca: Confederación de Asociaciones Empresariales de Baleares e Instituto Balear de Promoción del Turismo.

Unidad de Promoción y Animación del Desarrollo Rural. (2006). Ocio y deporte en el medio rural. Actualidad Leader, 33, octubre, s. p.

U.T.E. Antar-Ecotono. (2004). El turismo de naturaleza en España y su plan de impulso. Madrid: Secretaría General de Turismo. Estudio inédito.

Vera Rebollo, F. et al. (1997). Análisis territorial del turismo. Barcelona: Ariel.

World Tourism Organisation. (1985). The role of recreation management in the development of active holidays and especial interest tourism and consequent enrichment of the holiday experience. Madrid: OMT. 